\title{
STRATEGIC ORGANISATIONAL TRANSFORMATION: THE ROLE OF LEARNING, LEADERSHIP AND CULTURE
}

\author{
K Viljoen \& HB Klopper (RAU)
}

Today's organisation need to continuously adapts itself to challenges, brought about by modern business environment. This paper argues that leadership, learning and culture play a major role in securing an organisation's ability to face and adapt to these new challenges.

\section{PURPOSE OF THE RESEARCH}

In understanding strategic organisational transformation, in an effort to secure long-term competitive advantage, this paper explains the necessity of

- the role of learning, in ensuring an organisation's ability to successfully transform itself into a learning organisation; focussing on

- the importance of an effective leadership style, enabling business to strategically align with the ability to adapt to change; and

- taking cognisance of the important role of culture in realising organisational transformation, gearing the organisation to adapt to the changing business environment.

\section{FACTORS INFLUENCING STRATEGIC ORGANISATIONAL TRANSFORMATION}

Strategic organisational transformation suggests a radical change in focus, as a result of changes in the marketplace and expectations of customers. It, however, also implies major internal matters in organisations, such as leadership, learning and culture, which will next be investigated more closely.

\section{The role of learning}

Several authors (Espejo et al. 1997:146; Sutton 1994:80 and Pérez-Bustamante 1999:8) have stressed the important role learning or the learning organisation plays in strategic organisation transformation. Tosey (1994:60) confirms that the concept of the learning company implies a need for new ways of thinking about organisations, and the ways of generating learning and change. According to the above authors, it is impossible for organisations to adapt continuously and successfully to the ever-changing environment without becoming a learning organisation. For this reason innovation and knowledge management, as strategic objectives, must be the centre of focus. Espejo et al. (1997:146) further state that a fundamental prerequisite for the survival of an organisation in the changing environment is the ability to adapt to change, which is the essence of 'learning'. Grieves (2000:65) however point out that learning has to be inspired by change, and further explains that because organisational environments are changing rapidly, one might perhaps agree that change, as a phenomenon, represents the very rationale for the necessity to learn.

The only reliable source of competitive advantage, according to Swain (1999:33) is the knowledge, which as the author has put it: "...is latent within the organisation itself in the memory and potential of employees". The key in unlocking it is to create a sense of identity between employee and organisation and to tap into the commitment generated. As with any learning organisation, a high trust climate is essential for this process to occur. A critical component of such organisations are a system, which continually distributes all necessary information available to workers and encourages the sharing of information and ideas. Therefore, management strategies must aim at ensuring the availability of information to employees, including the conceptual frameworks to enable them to use that information for organisational ends. Fast learning organisations should encourage networking 
and information sharing, cross-functional teamwork, encourage holistic systems thinking and in addition to narrow problem solving and expert creativity, focus on innovation and continuous learning - rather than conformity - from managers and employees (Martensen \& Dahlgaard 1999:888).

Espejo et al. (1997:296) explain that in the organisational context of strategic management, the object is to discover how organisations learn and acquire, and then maintain and enhance, strategically relevant organisational properties, such as the following:

- responsiveness - sensitivity to challenges, in other words to opportunity and risk;

- capacity for innovation - the finding, evaluation and implementation of new ideas;

- adaptability - adaptation to external change;

- flexibility - reaction to problems; and

- communication competence - scope of treatment, intensity of communication and rules for reaching a consensus on important and especially, on controversial subjects.

Finally, Grieves (2000:64) suggests that organisational learning today is both a stimulus to and results from organisational change and development in order to achieve competitive advantage through knowledge work.

\section{The role of leadership}

Transformational change requires managing from the top, and as Beeby \& Simpson (1995:20) confirm: "...employees must have a clear, consistent and compelling picture of the goals of their changing organisation, which is only possible with a clear vision of the organisation shared by management and employees." The authors furthermore describe the dynamics of top management teams pointing out that such teams work to facilitate visible and unified leadership from a committed and cohesive management team, which involves developing a climate of openness, trust and risk taking between team members, as also confirmed by Schneider \& Goldwasser (1998:42).

Espejo et al. (1997:333) argue that in today's organisation marked by continuous transformation, effective leadership is increasingly based on conceptual and interpersonal competency rather than technical competencies. Furthermore, Shields (1999:106) notes that successful executives truly believe that people are their greatest asset. With effective leadership, the value of employees' actions can be optimised to realise higher growth, greater shareholder value and sustained competitive advantage. Schneider \& Goldwasser (1998:42) stress the importance of the fact that a leader in transformation must link change to key business processes and performance measures, set goals for the change effort using these measures and then track and report on progress against goals. A key leadership duty, according to the above authors, is the defining of the values and beliefs that can be used to shape behaviours and ultimately performance. The above can be supported by the SevenLever Model as described by Shields (1999:106), that pays attention to the critical success components that are available to leaders to achieve their overall strategy and desired results (Figure 1). It is important to note that leadership stands central to the corporate strategy, in context of the change levers as described by Shields (1999:106).

According to Yukl (1994:360) leaders involved in the transformational process must have a few necessary characteristics to enable strategic transformation, which include the ability to

- recognise the need for change and to persuade other key people in the organisation to understand the seriousness for the need for change;

- to manage the transition process by effectively diagnosing and addressing problem areas and dealing with people resisting the change and who find it hard to reject old beliefs and values; and

- to create a new vision and find ways to inspire people with this vision of a better future. 
Figure 1: The Seven-Lever Model

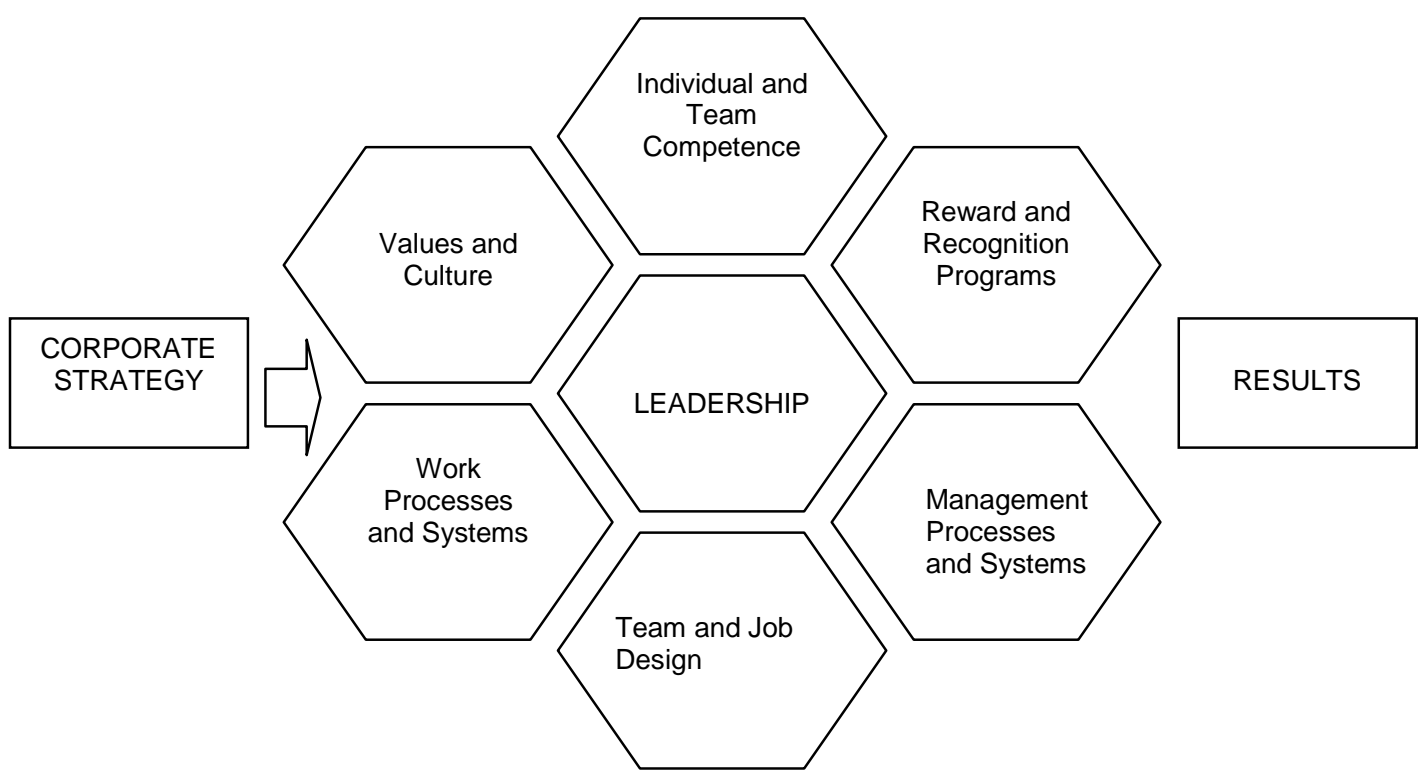

Source: Shields 1999:xx

Therefore, to effect transformation, the leaders must institutionalise the change, which can be done by determining whose commitment is necessary for changes in structure, policies and strategies and getting that support and co-operation.

\section{The role of culture}

Bowman \& Asch (1996:87) explains that a key issue in strategy is the extent to which the values, beliefs and assumptions are held in common by members of an organisation, which would also influence the implementation of strategic change. Hussey (1996:246) writes that on many occasions strategic change requires a change in company culture, in which case, a training initiative may be one of the most powerful tools that can be used. In this regard, Langdon \& Bruce (1997:312) state that changing culture, like changing emotions, is not an easy subject to deal with, and therefore it is important that the organisation and the people in it, must be willing and able to make the change. It can for this reason be argued that failure to build an appropriate culture is not caused by a stubborn refusal to change by an antiquated workforce, but rather by a lack of clear vision and guidance in how to change. Organisational change and culture are therefore closely related. Without the necessary support from an adaptive culture, organisational change will be very difficult to accomplish. A number of different views on the relationship between culture and change exist. Thompson \& Strickland (1999:340) write that in adaptive cultures, which are characteristic of organisations that can transform themselves successfully, members share a feeling of confidence that the organisation can deal with whatever threats and opportunities come down the pike; they are receptive to risk-taking, experimentation, innovation, and changing strategies and practices whenever necessary to satisfy the legitimate interests of stakeholders - customers, employees, shareowners, suppliers, and the communities where the company operates. 


\section{STRATEGIC ORGANISATIONAL TRANSFORMATION}

According to Appelbaum et al. (1998:291) strategic organisational change can emanate from two different sources, namely

- from either the external environment such as changes in competitors' actions, government regulations, economic conditions and technological advances, or

- change can originate from within the organisation, which could be a new corporate vision or mission, the purchase of new technology, mergers and acquisitions and the decline in morale in the company.

Senior (1997:23) states that forces for change within an organisation are frequently the result of some external influences. It is also certain that organisations that do not respond to triggers such as increasing competition, new legislation or the expectations of customers will soon decline and may cease to exist.

In order to ensure their long-term survival, it is evident from the above that organisations must develop skills in strategic transformation (Stockport 2000:51). This means more than simply implementing a strategic planning system. It involves a realisation that markets and customers will radically change. Thompson (1997:26) points out that strategic management involves awareness of how successful and strong the organisation and its strategies are, and how circumstances are changing. Therefore at any time, previously sound products, services and strategies are likely to be in decline. When it happens new 'windows of opportunity' are opening, which can be explained in terms of the organisational life cycle as depicted in Figure 2. Rowe et al. (1994:490) agree that the dynamics of organisational change are linked to the organisational life cycle. Also Farrell (1996:194) explains that companies, like everything else in the world, must contend their own life cycle identifying its creation, followed by growth, growth peaks and decline sets in, leading ultimately to death.

\section{Figure 2: Organisational life cycle}

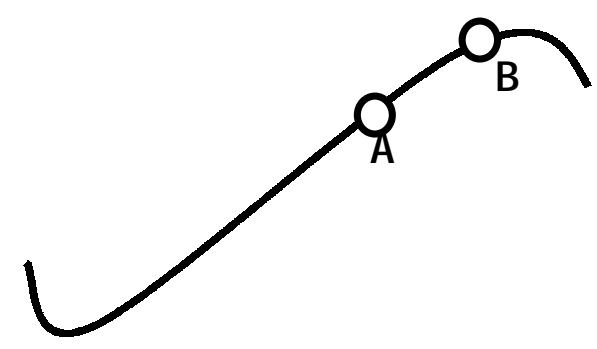

Source: Stockport 2000:46

According to Stockport (2000:46) the organisational life cycle of an organisation grows up to a point (A) but eventually start to wither and die at point $(B)$ as shown in Figure 2. From a strategic transformation standpoint, position $(A)$ is the most important point on the curve because it represents the last point possible for an organisation to transform itself strategically before it starts to wither. Here the leadership of the organisation plays an important role in identifying that point in time when an organisation can still proactively transform itself. Leaders must make sure that the necessary processes and procedures are in place and the organisation is equipped to respond to the transformation once it reaches that point in time. After point $(A)$, strategic transformation will be reactive rather than proactive and the organisation will be forced to change. The successful organisations of the future will have to be foresighted and opportunistic and be a learning organisation where knowledge management and innovation will determine the effective utilisation of the 'window of 
opportunity'. In terms of the window of opportunity, Point (A) is defined as a strategic inflection point and it is at this point that the organisation will either grow to new heights or it will decline. It is therefore important for managers to accept that their organisational life cycle is probably S-shaped too and they must make a judgement as to where they are on the curve. Relating to organisational life cycles, Rowe et al. (1994:490) point out that the organisational life cycle, which includes creation, transformation and decline, can help management to determine what intervention strategies are appropriate for organisational change and at what stage in the organisation's development should strategic organisational transformation be introduced.

\section{MAJOR RESULTS}

Many organisations lose momentum and are unable to achieve the sustained results because they do not consider the importance of factors such as leadership, learning or culture in driving change, which forms the most critical components of strategic organisational transformation. This paper argued that the leader within the organisation drives the strategy and suggested that if organisations are able to gear itself, through an adaptive culture to be ready and respond to new challenges by constantly adapting to change, conditions are favourable to secure long-term competitive advantage.

\section{IMPLICATIONS}

An organisation's competitive advantage today is not linked to its ability to capitalise on new technology or products, as competitors are able to quickly follow the market leader and also use the technology or provide the product. Sustained competitive advantage seemed to be determined by the knowledge and expertise available in the organisations' ability to seize the strategic 'windows of opportunity' where employees will be able to create new and innovative concepts and ideas to enable organisations to stay the market leaders. It is entrenched in the organisation's ability, through effective leadership to adapt its culture and to develop dynamic capabilities, which are the organisations ability to learn, to adapt change, and renew over time.

\section{BIBLIOGRAPHY}

APPELBAUM SH, ST-PIERRR N \& GALVAS W. 1998. Strategic organizational change: the role of leadership, learning, motivation and productivity. Management Decision, 35(5):289-301.

BEEBY M \& SIMPSON P. 1995. Developing strategic processes for change in top management teams. Executive Development, 8(1):20-22.

BOWMAN C \& ASCH D. 1996. Managing Strategy. London : Macmillan.

ESPEJO R, SCHUMANN W, SCHWANIGER M \& BILELLO U. 1997. Organisational transformation and learning. Chichester: Wiley.

FARRELL LC. 1996. Searching for the spirit of the enterprise. In Hussey D. ed. The Implementation Challenge. Chichester: Wiley.

GRIEVES J. 2000. Navigating change into the new millennium: themes and issues for the learning organization. Learning Organization, 7(2):54-74.

HUSSEY DE. 1996. Management training: a key tool for strategy implementation. In Hussey D. ed. The Implementation Challenge. Chichester: Wiley. 
LANGDON K \& BRUCE A. 1997. Creating a market sensitive culture. London: Pitman.

MAARTENS A \& DAHLGAARD JJ. 1999. Strategy and planning for innovation management - supported by creative and learning organizations. International Journal of Quality and Reliability Management, 16(9):878-891.

PéREZ-BUSTAMANTE G. 1999. Knowledge management in agile innovative organizations. Journal of Knowledge Management. 3(1):6-17.

ROWE AJ, MASON RO, DICKEL KE, MANN RB \& MOCKLER RJ. 1994. Strategic Management: a methodological approach. $4^{\text {th }}$ ed. Massachusetts: Addison-Wesley.

SCHNEIDER DM \& GOLDWASSER C. 1998. Be a model leader for change. Management Review, 87(3):41-46.

SENIOR B. 1997. Organisational Change. London: Pitman.

SHIELDS JL. 1999. Transforming organisations: methods for accelerating culture change process. Information, Knowledge and Systems Management, 11:105-115.

STOCKPORT GJ. 2000. Developing skills in strategic transformation. European Journal of Innovation Management, $3(1): 45-52$.

SUTTON D. 1994. Levels of learning in organizations. In BURGOYNE J, PEDLER M \& BOYDELL T eds. Towards the learning Company. Berkshire: McGraw-Hill.

SWAIN P. 1999. Organizational learning: developing leaders to deal with continuous change - a strategic human resource perspective. Learning Organization, 6(1):30-37.

THOMPSON JL. 1997. Lead with vision: manage the strategic challenge. London: International Thompson.

THOMPSON AA \& STRICKLAND AJ. 1999. Strategic Management: cases and concepts. $11^{\text {th }}$ ed. Singapore: Irwin/McGraw-Hill.

TOSEY P. 1994. Energies of organization and change.. In BURGOYNE J, PEDLER M \& BOYDELL T eds. Towards the learning Company. Berkshire: McGraw-Hill.

YUKL G. 1994. Leadership in Organizations. $3^{\text {rd }}$ ed. New Jersey : Prentice Hall. 